\title{
THE THANKSGIVING MEETING IN ANN ARBOR
}

The two hundred seventy-third regular meeting of the Society was held at the University of Michigan on Friday and Saturday, November 29-30, 1929. About ninety persons attended the meeting, among whom were the following sixtythree members of the Society:

B. E. Allen, W. L. Ayres, Barnett, Beale, G. A. Bliss, Blumberg, Bradshaw, Bushey, Churchill, Clack, A. H. Copeland, Copp, Dancer, H. T. Davis, Denton, Dushnik, P. D. Edwards, L. C. Emmons, Peter Field, Fisk, Folley, Fort, Gehman, J. W. Glover, L. M. Graves, Grennan, V. G. Grove, Hildebrandt, L. A. Hopkins, Ingraham, E. H. Johnson, L. S. Johnston, Karpinski, W. S. Kimball, Kuhn, Langford, Latimer, C. E. Love, McShane, Merriman, C. N. Moore, D. C. Morrow, A. L. Nelson, Nyswander, H. L. Olson, Parkinson, Plant, Pollard, V. C. Poor, Raiford, Rainich, Rasor, W. T. Reid, C. E. Rhodes, Ross, Roth, Running, Simmons, Speeker, Teach, J. H. Weaver, K. P. Williams, C. O. Williamson.

On Friday afternoon Professor Tomlinson Fort gave an address on The general theory of factorial series, and Professor L. M. Graves addressed the Society on Discontinuous solutions in the calculus of variations. Both of these addresses will appear in early issues of this Bulletin.

On Friday evening members and their guests attended a dinner at the Michigan Union. Professor Glover welcomed the Society to the University of Michigan and called on Professor Bliss to speak. Seventy-three attended the dinner.

Saturday morning a rising vote of thanks to the Department of Mathematics of the University of Michigan and others who had contributed to the entertainment of the Society was passed.

The titles and cross-references to the abstracts* of the papers read at this meeting follow below. Papers 1-7 were read on Friday morning, and papers 8-18 on Saturday morning. Paper 16 , whose abstract number is accompanied by the letter $t$, was read by title. Mr. Abernethy was introduced by Professor Running, Dr. Baten and Mr. Chang by Professor Rainich, and Mr. Latshaw by Professor H. T. Davis. Professor Glover presided Friday morning; Professor Field, Friday afternoon; and Professors Bliss and C. N. Moore, Saturday morning.

1. Exterior motion in the restricted problem of three bodies, by Professor C. J. Coe. (Abstract No. 36-1-26.)

\footnotetext{
* See the footnote on page 6 .
} 
2. Pairs of curves in an $S_{n}$, by Professor G. A. Parkinson. (Abstract No. 36-1-27.)

3. Centers of symmetry in analysis situs, by Professor H. M. Gehman. (Abstract No. 36-1-28.)

4. An investigation of surfaces in euclidean 4-space by means of 3-vectors, by Mr. N. C. Fisk. Preliminary report. (Abstract No. 36-1-29.)

5. Polynomial approximation by the method of least squares, by Professor H. T. Davis and Mr. V. V. Latshaw. (Abstract No. 36-1-30.)

6. A general explicit formula of numerical integration, by Mr. J. R. Abernethy. (Abstract No. 36-1-31.)

7. A calculus of variations problem whose extremals are parabolas, by Professor H. A. Simmons. (Abstract No. 36-1-32.)

8. The Hamilton-Jacobi theory for the problem of Lagrange in parametric form, by Professor V. B. Teach. (Abstract No. 36-1-33.)

9. Simultaneous treatment of discrete and continuous probabilities by use of Stieltjes integrals, by Dr. W. D. Baten. (Abstract No. 36-1-34.)

10. Gibbs' phenomenon in summable series of Bessel's functions, by Professor C. N. Moore. (Abstract No. 36-1-35.)

11. Some transformations of linear partial differential equations, by Mr. H. C. Chang. (Abstract No. 36-1-36.)

12. Note on an infinite system of linear differential equations, by Dr. W. T. Reid. (Abstract No. 36-1-37.)

13. On representation of integers by definite ternary quadratic forms whose determinant contains no square factors, by $\mathrm{Mr}$. A. E. Ross. (Abstract No. 36-1-38.)

14. Nilpotent and idempotent algebras of infinite order, by Professor M. H. Ingraham. (Abstract No. 36-1-39.)

15. Residues of polygenic functions, by Professor V. C. Poor. (Abstract No. 36-1-40.)

16. Permutable functions in the complex domain, by Dr. L. M. Blumenthal. (Abstract No. 36-1-41-t.)

17. Sphere geometry and conformal transformations in function space, by Professor I. A. Barnett. (Abstract No. 36-1-42.)

18. The first variation of a triple integral in the case of variable limits, by Professor H. A. Simmons. (Abstract No. 36-1-43.)

MARK H. IngRAHAM, Associate Secretary 